Research Paper:

\title{
Determining the Mediating Role of Psychological Well- crossuark Being in the Relationship Between Spiritual Intelligence and Life Satisfaction of Nurses Working in Lamerd City
}

Seyed Ahmad Hashemi ${ }^{1 *}$, Abolfazl Abbasi ${ }^{1}$

1. Department of Educational Sciences, Faculty of Humanities, Lamerd Branch, Islamic Azad University, Lamerd, Iran

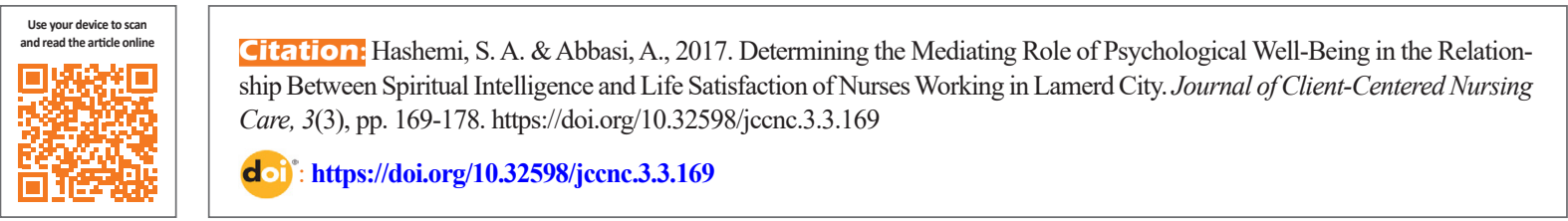

Article info:

Received: 06 Oct. 2016

Accepted: 30 Apr. 2017
Keywords:

Life satisfaction, Psychological wellbeing, Healthcare provider, Spiritual intelligence

\begin{abstract}
A B S T RA C T
Background: Considering the satisfaction of the life of the healthcare workers, it is imperative that they are exposed to mental health problems. In this regard, improving spiritual intelligence and paying attention to the psychological well-being of employees can help in the satisfaction with the lives. Accordingly, the present study aimed to determine the mediating role of psychological well-being in the relationship between spiritual intelligence and life satisfaction of nurses working in Lamerd city.

Methods: In the present study descriptive-correlation method was applied. The statistical population of the study included 110 nurses working in the city of Lamerd. Due to the limited population nurses were included in the research using the census method of all members of the community. To collect data, three standard questionnaires of spiritual intelligence, Badie et al., Carole Reef's Welfare Scale and Life satisfaction scale of Diner et al. were used. The reliability of the tool was calculated to be $0.87,0.83$ and 0.81 , using Cronbach's alpha, respectively. The data analysis process was performed using statistical correlation, regression, and structural equation modeling in Lisrel and SPSS V. 19 software.
\end{abstract}

Results: According to the results, there was a positive and significant relationship between the spiritual intelligence $(r=0.41, P<0.01)$ and the life satisfaction of nurses and between psychological well-being and life satisfaction of nurses $(r=0.46, P=0.01)$. There was a positive and significant relationship between spiritual intelligence $(\mathrm{r}=0.38, \mathrm{P}<0.01)$ with psychological well-being of nurses and healthcare providers. Also, the path coefficients of spiritual intelligence dimensions were compared from stage one to stage three. By reducing the coefficients of the direct path, the general thinking and belief in life satisfaction (from 0.34 to 0.28 ), the ability to cope and interaction with problems on life satisfaction (from 0.38 to 0.32 ), self-awareness and love (from 0.33 to 30 ), moral satisfaction on satisfaction from life (from 0.27 to 0.23 ), the psychological well-being variable was mediated predictor of the relationship between the dimensions of spiritual intelligence and life satisfaction.

Conclusion: The results demonstrated that there is a positive and significant relationship between spiritual intelligence and psychological well-being with life satisfaction of nurses and healthcare providers. In this regard, psychological well-being plays a mediating role between spiritual intelligence and life satisfaction.

\section{* Corresponding Author:}

Address: Department of Educational Sciences, Faculty of Humanities, Lamerd Branch, Islamic Azad University, Lamerd, Iran.

Tel: +98 (917) 7823024

E-mail: hmd_hashemi@yahoo.com 


\section{Background}

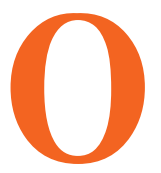

ver the past decade, and with the spread of real psychological topics, the desire to study positive aspects of health has been increasing alongside with negative aspects. One of these concepts taken into consideration is the concept of life satisfaction. Life satisfaction is a positive-emotional evaluation of life. These evaluations consist of emotional responses to events, as well as cognitive judgments of satisfaction. Life satisfaction indicates how one evaluates overall life, and focuses on assessing the extent to which a person makes his or her life. Lifestyle satisfaction can be defined as the judgment of the individual about all domains of life at a particular point in time or as an integrated judgment of the person's life from birth (Diener \& Napa Scollon 2003).

In fact, life satisfaction reflects these issues to what extent basic needs have been met and to what extent other types of goals are achievable goals. While for those who live in underdeveloped conditions, the satisfaction of basic needs is more relevant (Schaller \& Neuberg 2012). Variables are influential on life satisfaction.

In recent decades, the scientific community has witnessed research in understanding and conceptualizing various aspects of positive psychology, especially wellbeing. Psychological well-being has been widely studied and has been conceptualized in various ways. Psychological well-being can be conceptualized according to emotional, physical, cognitive, spiritual, individual and social processes. Theoretical dimensions of positive psychological health from Riff's point of view include independence, environmental mastery, individual growth, positive relationships with others, the purpose of life, and acceptance (Mount, Boston \& Cohen 2007).

The World Health Organization defines psychological well-being as "Complete physical, social, psychological well-being, and the absence of illness and weakness, the ability to communicate in harmony with others and change the individual and social environment (Zhang, Shi \& Cheng 2017).

Psychological well-being requires understanding the existential challenges of life. The psychological wellbeing approach examines the evolution observed against the existential challenges of life, and heavily emphasizes human development, such as pursuing meaningful goals, transforming and advancing as a person, and establishing quality relationships with others. An exten- sive collection of research literature from the 1950s and 1960s has been devoted to analyze the challenges and fundamental problems of life (Urhahne \& Zhu 2015).

Therefore, considering that psychological well-being is in the field of positive psychology and has been less well received in recent years about psychological pathology issues, it can provide a satisfactory life by creating an internal strength approach (Samani, Jokar \& Sahragard 2009).

Therefore, considering that psychological well-being is in the field of positive psychology and has been less well received in recent years about psychological pathology issues, it can provide a satisfactory life by creating an internal strength approach (Kézdy et al. 2011).

Accordingly, many scholars suggest that by introducing divine teachings into the knowledge of existential nature of human and their psychological aspect, and also taking into account the factors that religion poses for calmness and confidence, an attempt is made to achieve a broader perspective than the mental concept and mental health (Dehaghi, Goodarzi \& Arazi 2012).

A correct image of health is to think of it as an unknown entity such as personality, mood, or happiness; multidimensional instruments that are a vast array of underlying phenomena. In the proposed conceptualization of health, there are three broad areas, suffering, functional ability, and peace of mind or inner subjective coherence in life. These domains, in addition to physical aspects, include cognitive, emotional, and spiritual aspects (Jafari et al. 2010)

There is a truth that people with higher spiritual intelligence practice specific virtues. This virtue is a desirable perfection that flows through spiritual people. As people practice the virtues in the workplace, they will bring significant benefits to the organization. For example, people with intellectual intelligence are always more committed to organizational commitment (Mahadevan 2013). They are more motivated (Duchon \& Plowman 2005) and more efficient and productive (Dent, Higgins \& Wharff 2005). Significant reasons for the interest in spiritual issues in the workplace can disappoint the workforce, the dissatisfaction with life, the increase in the uncertainty of senior management, the increased demand for more and more profits and the reduction of employee health (Reave 2005).

The spiritual intelligence of employees is crucial for achieving organizational success. Today, the organiza- 
tion's managers are looking for ways to increase the level of spiritual and religious teachings of the staff to increase the level of satisfaction of their employees and to achieve "excellence." Those who have high spiritual intelligence can relieve stress due to the adherence to the superior force and the use of spirituality; these people find more than anyone else in psychological crises and semantic problems to learn through this. Spiritual people have well-behaved behaviors such as forgiveness, generosity, humanity, compassion, and love.

The results of this study demonstrated that spirituality affects the overall satisfaction of life. Personal spirituality predicts a higher level of satisfaction with life. It is also evaluated as an adaptive mechanism that helps them to control better stressors than those who have a lower level of personal spirituality (Mohamad, Mokhtar \& Samah 2011).

The study demonstrated that leaders with high spiritual intelligence have five effective leaders ahead of others: challenging the collective vision, empowering others, modeling work, and encouraging the heart (Williams \& Allen 2014). According to another study, it can be said that the four main dimensions of human interconnected: physical body, thoughts, emotional affections, and soul. Leaders must also recognize their fundamental values and motivate them through their vision and actions to motivate their followers to create a sense of membership and spiritual mission (Yonker 2012). In the study of the relationship between spiritual beliefs and the satisfaction of African American women, another study demonstrated that women with a higher level of spiritual bias had higher levels of income and higher life satisfaction (Moritz 2011). Religious customs are considered as group activities that change people and their relationships. These social activities give power to members of the group and lead people to groups and group values (Wills-Herrera, 2011).

Research also showed that there is a definite and significant correlation between job satisfaction and its different aspects with the mental health of staff, and the lack of appropriate opportunities for promotion can lead to mental problems (Mihaljevic et al. 2016). Accordingly, spiritual intelligence can provide the basis for psychological well-being. Furthermore, since psychological well-being can improve the satisfaction of the employees' lives, considering this issue is of great importance. In this regard, health centers and hospitals should be considered as organizations whose employees are exposed to various types of mental health and injury.

\section{Materials and Methods}

This study was a descriptive-correlative and descriptive-applied. In this study, psychological well-being and spiritual intelligence were predictor variables, and variable of life satisfaction was a criterion variable. The statistical population of the study consisted of 110 nurses working in Lamerd city. To ensure the accuracy of the results of this study, the whole group was included in the census. In this study, three standard questionnaires were used to collect information, i.e. Spiritual Intelligence Questionnaire; Scale of Psychological Well-being; and Life Satisfaction Scale.

\section{Spiritual Intelligence Questionnaire}

In this study, Spiritual Intelligence Questionnaire (Badiie et al. 2010) was used to measure the spiritual intelligence variable. This questionnaire is in the Likert range (I totally agree (score 5), I agree (grade 4), I have no idea (score 3), I disagree (score 2), I totally disagree (score 1)). The questionnaire has 4 levels of general thinking and trust, the ability to deal with problems, ethical issues and self-awareness and love and interest. The reliability of this tool was calculated using Cronbach's alpha, with a total reliability of 0.87 .

\section{Scale of Psychological Well-Being}

The Scale of Psychological Well-being was created by Carroll Reiff in 1989. This scale covers 84 questions and six factors. To investigate the validity of the tool and measure its relationship with the personality traits and also the psychological well-being index, Riff used measures such as Bradburn's Scale of Psychologic WellBeing (also known as The Affect Balance Scale) and Rosenberg Self-Esteem Scale. This questionnaire is in the Likert range (I totally agree (score 5), I agree (grade 4), I have no idea (score 3), I disagree (score 2), I totally disagree (score 1)). This scale has also been standardized in Iran. Reliability of this tool was calculated again using Cronbach's alpha, with a total reliability of 0.83 .

\section{Life Satisfaction Scale}

This scale was developed by Diner and his colleagues in 1985 and consists of five propositions that measure the cognitive component of the subject's well-being. The subjects say that, e.g. they are happy with their lives or how close they are to their ideal life. Each statement has seven options that are scored from 1 to 7. This scale is available as a group. In this research, Cronbach's alpha was used to obtain the reliability of 
the questionnaire, which was 0.81 which indicates the reliability of the questionnaire.

\section{Results}

According to the data of Table 1, spiritual intelligence $(\mathrm{r}=0.41, \mathrm{P}=0.01)$ and its subscales of general thinking and beliefs $(r=0.36, P=0.01)$, coping ability And interaction with problems $(\mathrm{r}=0.39, \mathrm{P}=0.01)$, self-awareness and love and affection $(\mathrm{r}=0.27, \mathrm{P}<0.01)$, and ethical issues $(\mathrm{r}=0.33, \mathrm{P}<0.01)$. There is a positive and significant relationship with the satisfaction of the life of nurses and health workers. According to Table 2, there is a positive and significant relationship between psychological well-being and life satisfaction of nurses and healthcare providers $(\mathrm{r}=0.46, \mathrm{P}=0.01)$. In addition to the above, the relationship between spiritual intelligence and psychological well-being is examined in Table 3.

According to Table 3, there is a significant relationship between spiritual intelligence $(\mathrm{r}=0.38, \mathrm{P}=0.01)$, general thinking and beliefs $(r=0.35, r=0.01)$, coping ability and interaction with problems $(\mathrm{r}=0.32, \mathrm{P}<0.01)$, self-awareness and love and affection $(\mathrm{r}=0.28, \mathrm{P}<0.01)$ and ethical issues $(\mathrm{r}=0.36, \mathrm{P}=0.01)$ with well-being. There is a positive and significant relationship between psychologists and nurses.

For further investigation, multiple regressions were used simultaneously according to the Baron and Kenny (1986) solutions. These steps include: 1. Regression of simultaneous thinking and beliefs, ability to cope with problems, self-awareness and love and interest and ethical issues on satisfaction with life; 2. Regression of simultaneous thinking and beliefs, ability to cope with problems, selfawareness and love, and interest and ethical issues on psychological well-being; 3. Regression of simultaneous psychological well-being on life satisfaction by controlling the variables of general thinking and belief, ability to cope with problems, self-awareness and love, interest and ethical issues; 4. Comparison of stages one and three; Regression coefficients of general thinking and beliefs, ability to cope with problems, self-awareness, love, and sting. Moral dream of a stage show declines in three of the mediating role of psychological well-being and satisfaction with life among these variables.
The first step is the regression of simultaneous thinking and beliefs, the ability to cope with problems, selfawareness, and love and interest, and moral queries on life satisfaction. Table 4 shows that the pillars of general thinking and belief, the ability to cope with problems, self-awareness, and love, interest, and ethical issues predict positive life satisfaction.

The second step is the simultaneous regression of general beliefs and beliefs, the ability to cope with problems, self-consciousness, love and interest, and ethical questions about psychological well-being. Table 5 demonstrates that overall thinking and belief, ability to cope with problems, self-awareness, love and interest and ethical issues predict positive psychological well-being.

The third step is the simultaneous regression of psychological well-being on life satisfaction by controlling the variables of general thinking and belief, the ability to cope with problems, self-awareness, and love and interest and ethical issues. The goal of this stage is to determine the mediating role of psychological well-being by controlling the variables of general thinking and belief, ability to cope with problems, self-awareness, and love, interest and ethical issues. Table 6 demonstrates that the variables of general thinking and belief, ability to cope with problems, self-awareness and love and interest, ethical issues and psychological well-being positively predict the life satisfaction of nurses and healthcare providers. The beta variables of general thinking and belief, the ability to cope with problems, self-awareness, and love and interest and ethical issues decreased from stage one to third, which indicates that psychological well-being between the variables of general thinking and belief, the ability to cope with problems, self-awareness and love, interest, and excitement, moral and life satisfaction have played a mediating role.

In the fourth stage, the path coefficients of the total variables of general thinking and belief, the ability to cope with problems, self-awareness, and love and interest and ethical issues were compared from step one to step three (Figure 2). By reducing the coefficients of the direct path, the general thinking and belief dimension on life satisfaction (from 0.34 in the Figure 1

Table 1. Correlation matrix test to examine the relationship between spiritual intelligence and its dimensions with life satisfaction

\begin{tabular}{cccccc}
\hline $\begin{array}{c}\text { Spiritual } \\
\text { Intelligence }\end{array}$ & Moral Queries & $\begin{array}{c}\text { Self-Awareness } \\
\text { and Love }\end{array}$ & $\begin{array}{c}\text { Ability to Deal With } \\
\text { Problems }\end{array}$ & Thinking and Trust & Variable \\
\hline $0.41^{* *}$ & $0.33^{* *}$ & $0.27^{* *}$ & $0.39^{* *}$ & $0.36^{* *}$ & Life satisfaction \\
\hline
\end{tabular}

** $\mathrm{P}<0.05$

Client-Centered Nursing Care 
Table 2. Correlation coefficient test to examine the relationship between psychological well-being and satisfaction with life

\begin{tabular}{ccc}
\hline & \multicolumn{3}{c}{ Life Satisfaction } \\
\cline { 2 - 3 } Variable & $\mathbf{r}$ & Sig. \\
\hline Psychological well-being & $0.46^{* *}$ & 0.001 \\
\hline
\end{tabular}

Table 3. Correlation matrix test to examine the relationship between spiritual intelligence and its dimensions with psychological well-being

\begin{tabular}{cccccc}
\hline Variable & $\begin{array}{c}\text { Thinking and } \\
\text { Trust }\end{array}$ & $\begin{array}{c}\text { Ability to Deal } \\
\text { With Problems }\end{array}$ & $\begin{array}{c}\text { Self-Awareness } \\
\text { and Love }\end{array}$ & Moral Queries & $\begin{array}{c}\text { Spiritual } \\
\text { Intelligence }\end{array}$ \\
\hline Psychological well-being & $0.35^{* *}$ & $0.32^{* *}$ & $0.28^{* *}$ & $0.36^{* *}$ & $0.38^{* *}$ \\
\hline
\end{tabular}

** $\mathrm{P}<0.05$

Client-Centered Nursing Care

Table 4. Simultaneous regression analysis to predict the satisfaction of life on the dimensions of spiritual intelligence

\begin{tabular}{|c|c|c|c|c|c|c|c|c|}
\hline Criterion Variable & Predestine Variable & Beta & $\mathbf{t}$ & $\mathbf{P}<$ & $\mathbf{R}$ & $\mathbf{R}^{2}$ & $\mathbf{F}$ & $\mathbf{P}<$ \\
\hline \multirow{4}{*}{ Life satisfaction } & Thinking and trust & 0.34 & 6.456 & 0.001 & \multirow{4}{*}{0.41} & \multirow{4}{*}{0.17} & \multirow{4}{*}{8.874} & \multirow{4}{*}{0.001} \\
\hline & Ability to deal with problems & 0.38 & 7.843 & 0.001 & & & & \\
\hline & Self-awareness and love & 0.33 & 5.780 & 0.001 & & & & \\
\hline & Moral queries & 0.27 & 3.768 & 0.012 & & & & \\
\hline
\end{tabular}

Client-Centered Nursing Care

Table 5. Analysis of simultaneous regression for prediction of psychological well-being on the dimensions of spiritual intelligence

\begin{tabular}{|c|c|c|c|c|c|c|c|c|}
\hline Criterion Variable & Predestine Variable & Beta & $\mathbf{t}$ & $\mathbf{P}<$ & $\mathbf{R}$ & $\mathbf{R}^{2}$ & $\mathbf{F}$ & $\mathbf{P}<$ \\
\hline \multirow{4}{*}{$\begin{array}{l}\text { Psychological well- } \\
\text { being }\end{array}$} & Thinking and trust & 0.33 & 6.101 & 0.001 & \multirow{4}{*}{0.38} & \multirow{4}{*}{0.14} & \multirow{4}{*}{7.800} & \multirow{4}{*}{0.001} \\
\hline & Ability to deal with problems & 0.29 & 4.346 & 0.001 & & & & \\
\hline & Self-awareness and love & 0.27 & 3.852 & 0.001 & & & & \\
\hline & Moral queries & 0.35 & 6.723 & 0.001 & & & & \\
\hline
\end{tabular}

Client-Centered Nursing Care

Table 6. Simultaneous regression analysis to predict the satisfaction of life on the dimensions of spiritual intelligence and psychological well-being

\begin{tabular}{ccccccccc}
\hline Criterion Variable & Predestine Variable & Beta & $\mathbf{t}$ & $\mathbf{P}<$ & $\mathbf{R}$ & $\mathbf{R}^{2}$ & $\mathbf{F}$ & $\mathbf{P}<$ \\
& Thinking and trust & 0.28 & 4.105 & 0.011 & & & \\
& Ability to deal with problems & 0.32 & 5.945 & 0.001 & & & & \\
\multirow{3}{*}{ Life satisfaction } & Self-awareness and love & 0.30 & 5.235 & 0.001 & 0.35 & 0.12 & 6.705 & 0.001 \\
& Moral queries & 0.23 & 2.950 & 0.041 & & & & \\
& Psychological well-being & 0.42 & 8.920 & 0.001 & & & \\
\hline
\end{tabular}

Client-Centered Nursing Care 


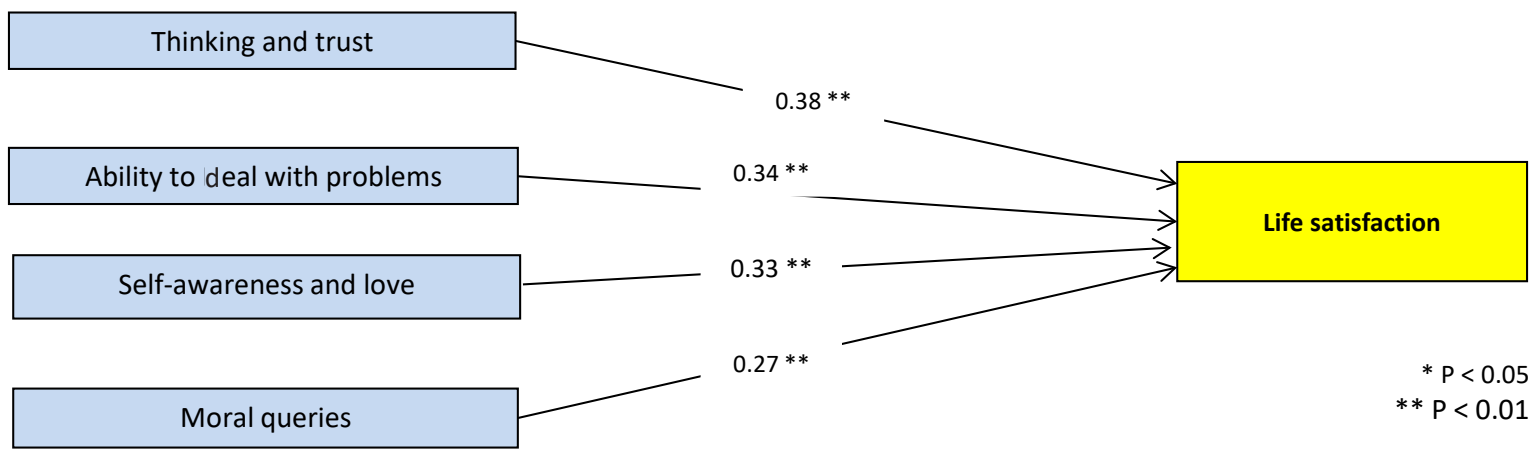

Client-Centered Nursing Care

Figure 1. The path coefficient of total thinking and beliefs, the ability to cope with problems, self-awareness, and love and interest, and moral queries on life satisfaction

to 0.28 in the Figure 3 ), coping ability and interaction with problems on life satisfaction (from 0.38 in the Figure 1 to 0.32 in the Figure 3), self-awareness and love (from 0.33 in the Figure 1 to 0.20 in the Figure 3 ), predict the variables of psychological well-being (from 0.27 in the Figure 1 to 0.23 in the Figure 3). The mediator was considered as the link between dimensions of spiritual intelligence and life satisfaction. The final results are presented in Figure 4.

Table 8 shows the direct and indirect effects of exogenous variables on the final inferiority. According to Table 8, the ratio of Q2 to the degree of freedom is equal to 0.00 . The RMSEA is also equal to 0.000 . RMSEA is 0.1. The GFI, AGFI and NFI indices are respectively $0.87,0.91$, and 0.93 , respectively, indicating fit fitness.

\section{Discussion}

The aim of this study was to determine the mediator role of psychological well-being in the relationship between spiritual intelligence and life satisfaction of nurses working in health centers in Lamerd. According to the results of this study, it can be speculated that there is a positive and significant relationship between spiritual intelligence and its subscales of general thinking and beliefs, coping ability and interaction with problems, selfawareness and love, interest, and ethical issues with life satisfaction of nurses and healthcare providers. Moreover, spiritual intelligence and its components positively predict life satisfaction. In explaining this finding, one can say that those who have high spiritual intelligence can more easily deal with stress. These people are more likely to learn in psychological crises and semantic problems than others, and grow up through these problems.

People with high spiritual intelligence have good behaviors such as forgiveness, generosity, humanity, compassion, and love. Spiritual intelligence helps to increase the stability and self-esteem of individuals and more easily cope with work issues. This improves the effectiveness and performance of individuals, improves communication and understanding of others in the workplace, and ultimately leads to the removal of barriers. Spiritual intelligence in the workplace can bring human-

Table 7. Direct, indirect, and all variables of research in the conceptual model of research

\begin{tabular}{|c|c|c|c|}
\hline \multirow{2}{*}{ Variable } & \multicolumn{3}{|c|}{ Types of Influence } \\
\hline & Direct & Indirect & Total \\
\hline Thinking and trust & 0.34 & 0.14 & 0.48 \\
\hline Ability to deal with problems & 0.38 & 0.12 & 0.50 \\
\hline Self-awareness and love & 0.35 & 0.15 & 0.42 \\
\hline Moral queries & 0.23 & 0.13 & 0.36 \\
\hline Psychological well-being & 0.42 & - & 0.42 \\
\hline
\end{tabular}


Table 8. Model fit indices

\begin{tabular}{ccc}
\hline Indicator & Standard Amount & Amount Earned \\
\hline RMSEA & Less than 3 & 0.00 \\
AGFI & Less than 1.0 & 0.000 \\
GFI & More than 0.8 & 0.87 \\
NFI & More than 9.0 & 0.91 \\
\hline
\end{tabular}

Client-Centered Nursing Care

ity to organizations for the activity and the responsible environment, and create the basis for the effectiveness of activities and ultimately life satisfaction. This finding is consistent with the study conducted by Yang and Mao (2007). They argue that using spiritual intelligence can solve the problems based on the value and status of the problem; we can also be aware of the performance and extent of the realization of our goals and satisfaction as a result of our behavior.

Another result of the research indicates that there is a definite and significant relationship between psychological well-being and nursing life satisfaction. These findings can be explained by speculating that psychological well-being is a kind of well-being in the mental, physical and social dimensions that make it possible to live on the circuit of success and positive thinking in one's person, thereby making mental health a satisfaction of life. From the perspective of the Reif, psychological well-being means trying to be perfect in realizing the real potential of a person. In this perspective, welfare means the attempt to transcend and promote that manifests itself in the realization of the individual's talents and abilities. Naturally, this behavioral approach can be a reason for life satisfaction. Given that nurses and medical person- nel are at risk with mental health, this variable can be a critical factor in explaining their life satisfaction.

Based on other findings, there is a positive and significant relationship between spiritual intelligence and its subscales of general domination and beliefs, coping ability and interaction with problems, self-awareness, love and interest, and moral queries with psychological well-being of nurses. Also, simultaneous regression demonstrated that spiritual intelligence and its dimensions positively predict psychological well-being. In this regard, it can be hypothesized that those who have high spiritual intelligence can relieve stress due to the adherence to the superior force and the use of religion, which is more than the other in psychological crisis and there are semantic problems to learn and grow through these problems. Spiritual people have well-behaved behaviors such as forgiveness, generosity, humanity, compassion, and love.

Finally, the results demonstrated that the variables of general thinking and belief, ability to cope with problems, self-awareness and love and interest and ethical issues and psychological well-being positively predict the satisfaction of nurses and health careers. In this regard, psychological well-being in the relationship Spiritual in-
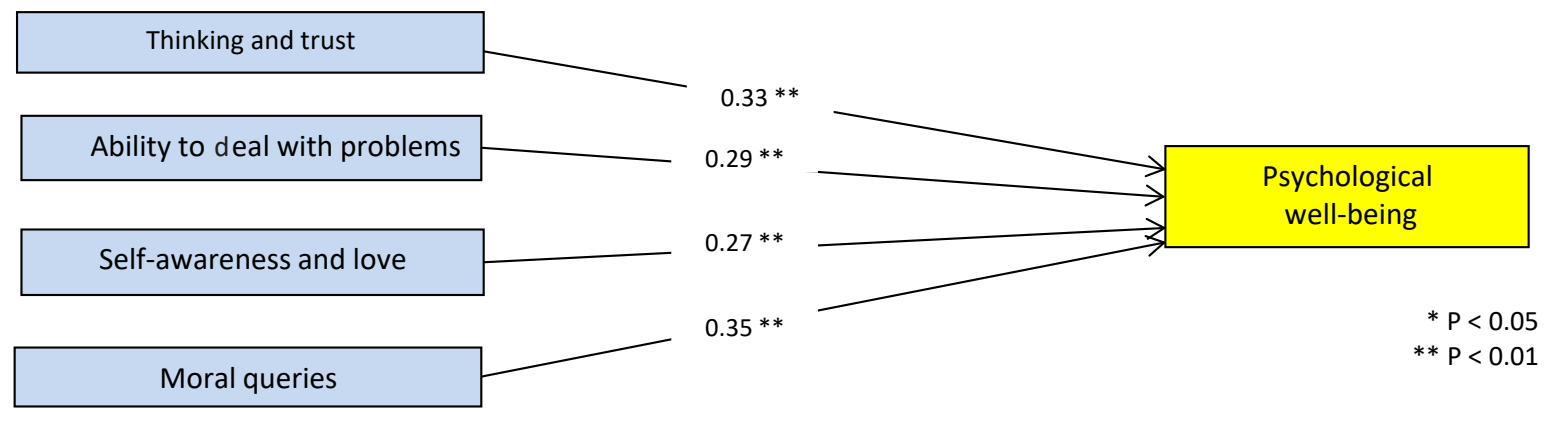
est and ethical issues on psychological well-being 


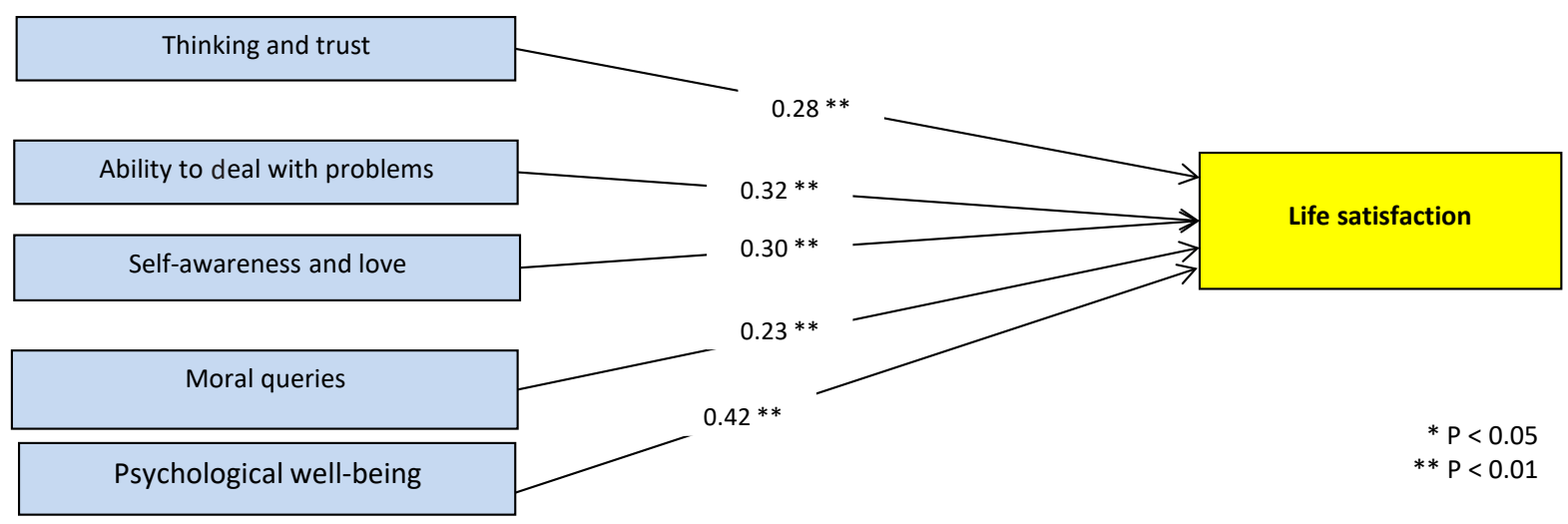

Client-Centered Nursing Care

Figure 3. The simultaneous effect of the dimensions of spiritual intelligence and psychological well-being on satisfaction with life

telligence and life satisfaction of nurses and health care providers play a mediating role. It can be hypothesized that spiritual intelligence is in the form of criteria of honesty, compassion, attention to all levels of consciousness, mutual sympathy, sensory existence that has an important role in a broader whole, forgiveness and spiritual and practical goodwill, in seeking compatibility and leveling up with nature and the well being, it is easy to be alone in the absence of a sense of loneliness; in fact, each of these criteria is the basis of psychological well-being. On the other hand, psychological well-being is also a criterion for life satisfaction. Hence, it can be speculated that spiritual intelligence, in addition to independently predicting positive and meaningful life satisfaction, can lead to satisfaction with life by predicting psychological well-being. In this regard, the results of many studies confirm this issue (Mohamad, Mokhtar \& Samah 2011; Moritz 2011; Mihaljevic et al 2016).
One of the limitations of this study is the lack of cooperation among patients in conducting the study, which requires justification by the authorities.

Based on the results of this study show the followings: Spiritual intelligence is a significant predictor of life satisfaction. It is imperative that university officials provide the ground for the promotion of the level of spiritual intelligence of nurses and healthcare providers; Considering that this study showed that life satisfaction with predictable psychological well-being is predictable, it is recommended that to maintain this relationship, psychological well-being and its components have a more meaningful approach in health centers and hospitals, taking on the wider context of the growing religious beliefs; Spiritual intelligence could predict psychological wellbeing; the basis for promoting mental health through spiritual intelligence is provided; Since the results of this study showed that spiritual intelligence through psycho-

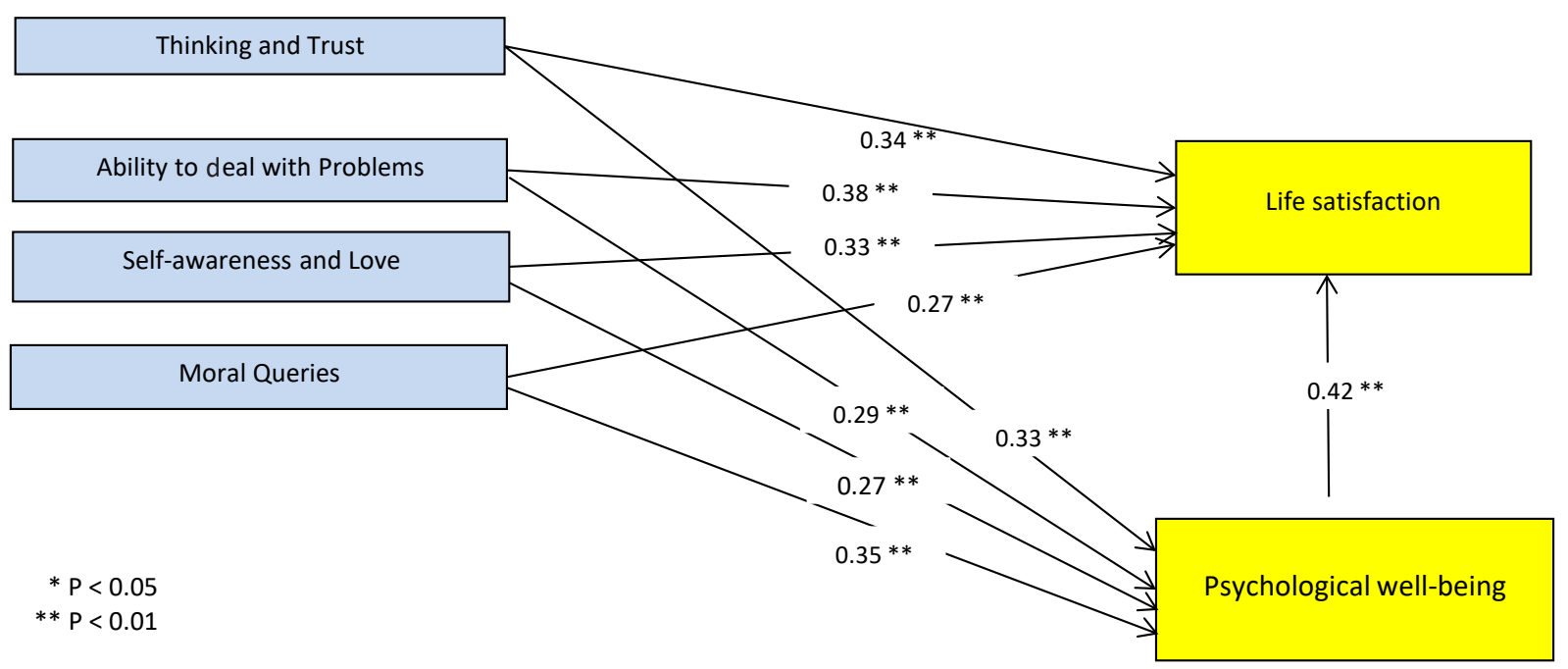

Figure 4. The final model in the entire group

Client-Centered Nursing Care 
logical well-being can predict life satisfaction, medical authorities are required to create a spiritual environment in the hospitals, and mental health centers to improve the quality of life in the light of these two variables; and Establish a mechanism for monitoring and evaluating the factors affecting life satisfaction.

\section{Acknowledgments}

This research was carried out with the participation and cooperation of Islamic Azad University of Lamard and Hazrat-e-Vali-e-Asr Hospital.

\section{Conflict of Interest}

The authors declared no conflicts of interest.

\section{References}

Badiie, A., Savari, E., Bagheri Dasht Bozorg, N. \& Latifizadegan, V. 2010. [Validation of Spiritual Intelligence Questionnaire (Persian)]. Paper presented at: The First National Conference on Psychology, 12-13 May 2010; Tabriz, Iran.

Baron, R. M. \& Kenny, D. A., 1986. The moderator-mediator variable distinction in social psychological research: Conceptual, strategic, and statistical considerations. Journal of Personality and Social Psychology, 51(6), pp. 1173-1182. [DOI:10.1037/00223514.51.6.1173]

Dehaghi, M. R., Goodarzi, M. \& Arazi, Z. K., 2012. The effect of spiritual values on employees' organizational commitment and its models. Procedia - Social and Behavioral Sciences, 62, pp. 159-66. [DOI:10.1016/j.sbspro.2012.09.025]

Dent, E. B., Higgins, M. E. \& Wharff, D. M., 2005. Spirituality and leadership: An empirical review of definitions, distinctions, and embedded assumptions. Leadership Quarterly, 16(5), pp. 625-53. [DOI:10.1016/j.leaqua.2005.07.002]

Diener, E., Napa Scollon, C. \& Lucas, R. E., 2003. The evolving concept of subjective well-being: The multifaceted nature of happiness. Advances in Cell Aging and Gerontology, pp. 187-219. [DOI:10.1016/S1566-3124(03)15007-9]

Duchon, D. \& Plowman, D. A., 2005. Nurturing the spirit at work: Impact on work unit performance. The Leadership Quarterly, 16(5), pp. 807-33. [DOI:10.1016/j.leaqua.2005.07.008]

Jafari, E. et al., 2010. Spiritual well-being and mental health in university students. Procedia - Social and Behavioral Sciences, 5, pp. 1477-81. [DOI:10.1016/j.sbspro.2010.07.311]

Kézdy, A. et al., 2011. Religious doubts and mental health in adolescence and young adulthood: The association with religious attitudes. Journal of Adolescence, 34(1), pp. 39-47. [DOI:10.1016/j.adolescence.2010.03.003]
Mahadevan, B., 2013. Spirituality in business: Sparks from the Anvil. IIMB Management Review, 25(2), pp. 91-103. [DOI:10.1016/j.iimb.2013.03.002]

Mihaljevic, S. et al., 2016. Do spirituality and religiousness differ with regard to personality and recovery from depression: A follow-up study. Comprehensive Psychiatry, 70, pp. 17-24. [DOI:10.1016/j.comppsych.2016.06.003]

Mohamad, M., Mokhtar, H. H. \& Samah, A. A., 2011. Personcentered counseling with malay clients: Spirituality as an indicator of personal growth. Procedia - Social and Behavioral Sciences, 30, pp. 2117-23. [DOI:10.1016/j.sbspro.2011.10.411]

Moritz, S. et al., 2011. A spirituality teaching program for depression: Qualitative findings on cognitive and emotional change. Complementary Therapies in Medicine, 19(4), pp. 201-7. [DOI:10.1016/j.ctim.2011.05.006]

Mount, B. M., Boston, P. H. \& Cohen, S. R., 2007. Healing connections: On moving from suffering to a sense of well-being. Journal of Pain and Symptom Management, 33(4), pp. 372-88. [DOI:10.1016/j.jpainsymman.2006.09.014]

Reave, L., 2005. Spiritual values and practices related to leadership effectiveness. The Leadership Quarterly, 16(5), pp. 655-87. [DOI:10.1016/j.leaqua.2005.07.003]

Samani, S., Jokar, B., \& Sahragard, N., 2007. [Effects of resilience on mental health and life satisfaction (Persian)]. Iranian Journal of Psychiatric and Clinical Psychology, 13(3):290-5.

Schaller, M., \& Neuberg, S. L., 2012. Danger, disease, and the nature of prejudice (s). In: James, M. O., \& Mark, p. Z., editors. Advances in experimental social psychology (pp. 1-54). Cambridge: Academic Press. [DOI:10.1016/B978-0-12-3942814.00001-5]

Urhahne, D., \& Zhu, M., 2015. Accuracy of teachers' judgments of students' subjective well-being. Learning and Individual Differences, 43, pp. 226-32. [DOI:10.1016/j.lindif.2015.08.007]

Williams, p. \& Allen, S., 2014. Faculty perspectives on the inclusion of spirituality topics in nonsectarian leadership and management education programs. The International Journal of Management Education, 12(3), pp. 293-303. [DOI:10.1016/j. ijme.2014.09.002]

Wills Herrera, E. et al., 2011. The relationship between perceptions of insecurity, social capital and subjective well-being: Empirical evidences from areas of rural conflict in Colombia. The Journal of Socio-Economics, 40(1), pp. 88-96. [DOI:10.1016/j. socec.2010.08.002]

Yang, K. P. \& Mao, X. Y., 2007. A study of nurses' spiritual intelligence: A cross-sectional questionnaire survey. International Journal of Nursing Studies, 44(6), pp. 999-1010. [DOI:10.1016/j ijnurstu.2006.03.004]

Yonker, J. E., Schnabelrauch, C. A. \& DeHaan, L. G., 2012. The relationship between spirituality and religiosity on psychological outcomes in adolescents and emerging adults: A meta-analytic review. Journal of Adolescence, 35(2), pp. 299-314. [DOI:10.1016/j.adolescence.2011.08.010]

Zhang, S., Shi, Q. \& Cheng, M., 2017. Renewable natural capital, the biocapacity, and subjective well-being. Journal of Cleaner Production, 150, pp. 277-86. [DOI:10.1016/j.jclepro.2017.03.021] 
August 2017 . Volume 3. Number 3

Client-Centered Nursing Care 